\title{
Thoracoscopic thoracic duct ligation for chylothorax after traumatic subclavian artery injury
}

\author{
Newton Roech Aerts, MD, Nilon Erling, Jr, and Paulo Roberto Ott Fontes, MD, Porto Alegre, Brazil
}

B lunt traumatic axillosubclavian vascular injury is an uncommon but challenging surgical problem. Because of the complex anatomic relationships in the upper mediastinum and thoracic outlet, associated injuries should always be investigated. Chylothorax after blunt chest trauma is a rare condition, ${ }^{1}$ and no reports of its association with subclavian artery injury have been found in the literature. We report a case of successful thoracoscopic thoracic duct ligation to treat chylothorax after blunt trauma with vascular injury.

\section{Clinical Summary}

A 23-year-old man sustained trauma to the anterior chest wall in a car accident. On admission, he was neurologically intact but complained of pain in the left shoulder and arm. He was tachycardic and hypotensive. Chest radiography revealed left clavicle fracture and left hemothorax. A left chest tube was inserted, and $1200 \mathrm{~mL}$ was drained initially. Exploratory thoracotomy was performed through a median sternotomy. An injury was found in the left subclavian artery. Left supraclavicular extension was performed for better visualization of the lesion. The artery was reconstructed with prosthetic graft interposition. The patient had an uneventful postoperative recovery and resumed oral intake on day 5. On the seventh day, he had increased pleural drainage of a milky appearance and absent radial pulse. Chylothorax and bypass graft thrombosis were suspected, and he was transferred to our hospital. On examination, his left upper arm was warm, but pulse was absent; Doppler ultrasonography was used to detect flow in all arteries, as well as in the graft. The patient underwent arteriography, which revealed an extrinsic compression of the graft, which almost occluded it. After this finding, surgical ligation of the thoracic duct was decided.

On the day before the operation, the patient was administered a contrast agent to help identify the duct. After achievement of general anesthesia, the right lung was deflated, and 4 trocar sleeves were inserted between the fifth and eighth intercostal spaces in the right hemithorax. The pulmonary ligament was transected, and the lung was retracted. The parietal pleura was incised low down in the chest over the azygos vein. A careful dissection exposed the

\footnotetext{
From the Department of Vascular Surgery, Complexo Hospitalar Santa Casa de Porto Alegre Fundação Faculdade Federal de Ciências Médicas de Porto Alegre, Porto Alegre, Brazil.

Received for publication Sept 22, 2005; revisions received Oct 9, 2005; accepted for publication Oct 26, 2005.

Address for reprints: Nilon Erling, Jr, Rua João Teles, n.280, apt.603, Bom Fim. Porto Alegre, RS—Brasil (E-mail: nilonjr@gmail.com).

J Thorac Cardiovasc Surg 2006;133:752-3

$0022-5223 / \$ 32.00$

Copyright $\odot 2006$ by The American Association for Thoracic Surgery doi:10.1016/j.jtcvs.2005.10.040
}

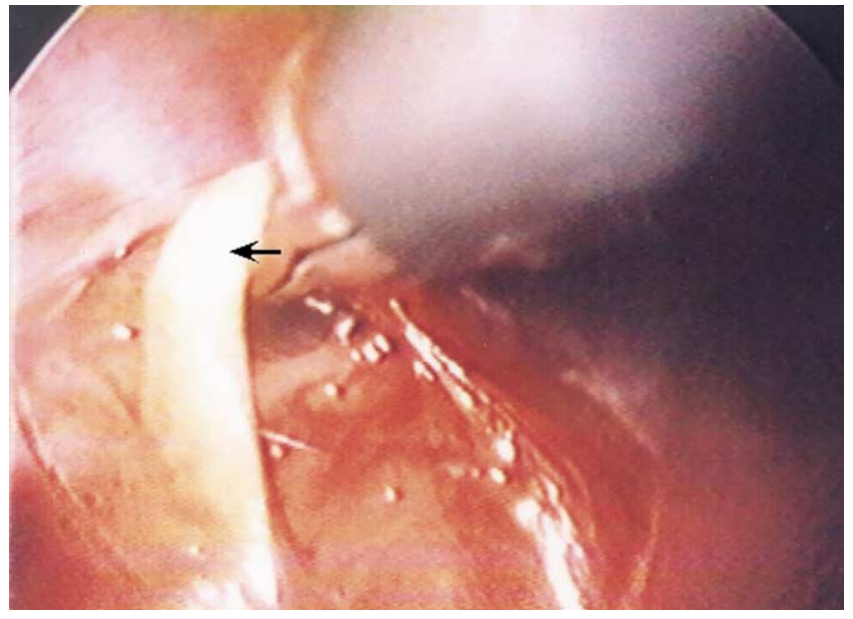

Figure 1. Thoracoscopic view of the thoracic duct (arrow) after incision of parietal pleura.

thoracic duct (Figure 1), which was then ligated. The recovery was uneventful, distal pulses of the left upper arm returned to normal, and the left chest tube was removed on the third postoperative day. The patient was followed up for 8 years without any sign of chylothorax recurrence.

\section{Discussion}

Innominate or subclavian artery injury, usually caused by penetrating trauma, remains a significant cause of mortality and morbidity. ${ }^{2}$ In blunt trauma the patient frequently experiences severe polytrauma, and a proper diagnosis should be promptly made to avoid delaying treatment. ${ }^{3}$ The surgical exposure of the subclavian or axillary vessels can be very difficult, especially in the presence of active bleeding. Despite growing enthusiasm for endovascular repair of these injuries, realistic clinical presentations and anatomic locations restrict the broad application of this technique. ${ }^{4}$

Chylothorax is a complex problem. In addition to the immune, metabolic, and nutritional consequences of extended chyle depletion, local problems can occur and cause compression of the lung or impairment of cardiac function. Moreover, vascular compression or graft thrombosis can be consequences of mechanical complications. Chylothorax is an uncommon finding in blunt thoracic trauma and might have a late presentation of several weeks. No reports of the association of blunt trauma with subclavian injury requiring vascular reconstruction and chylothorax were found in the literature.

The management of chylothorax is initially conservative, and no consensus on the indications for surgical intervention has been 
reached. Suggested guidelines are as follows: chyle leak of greater than $1 \mathrm{~L}$ per day for more than 5 days or persistent leak for more than 2 weeks of treatment. These guidelines have been drawn on the basis of the comparison of conservative treatment with thoracotomy and not on the setting of thoracic trauma. The advent of video-assisted thoracoscopic surgery over the last decade has changed the approach to the management of a number of chest diseases. Because of the lower morbidity associated with videoassisted thoracoscopic surgery (less pain and pulmonary dysfunction), the guidelines regarding the timing of surgical intervention must be reviewed. ${ }^{5}$ In the case reported here, we adopted an early surgical intervention approach because of vascular compromise of the left upper arm despite pleural drainage.

The thoracic duct was reached through the right pleural cavity, although the chylothorax was in the left. The advantages of this access route are fewer anatomic variations of the duct at the point where it enters the thorax and a cleaner operating area free of previous dissections, fibrin clots, or an incarcerated lung.

\section{References}

1. Dulchavsky SA, Ledgerwood AM, Lucas CE. Management of chylothorax after blunt chest trauma. $J$ Trauma. 1988;28:1400-1.

2. Cox CS Jr, Allen GS, Fischer RP, Conklin LD, Duke JH, Cocanour CS, et al. Blunt versus penetrating subclavian artery injury: presentation, injury pattern, and outcome. J Trauma. 1999;46:445-9.

3. Aerts NR, Poli de Figueiredo LF, Burihan E. Emergency room retrograde transbrachial arteriography for the management of axillosubclavian vascular injuries. J Trauma. 2003;55:69-73.

4. Danetz JS, Cassano AD, Stoner MC, Ivatury RR, Levy MM. Feasibility of endovascular repair in penetrating axillosubclavian injuries: a retrospective review. J Vasc Surg. 2005;41:246-54.

5. Kumar S, Kumar A, Pawar DK. Thoracoscopic management of thoracic duct injury: is there a place for conservatism? J Postgrad Med. 2004; 50:57-9.

\title{
Two-staged treatment of bronchial carcinoid without pulmonary parenchymal resection
}

\author{
Motoyasu Sagawa, MD, Makoto Sugita, MD, Sumiko Maeda, MD, and Tsutomu Sakuma, MD, Uchinada, Ishikawa, Japan
}

T ypical carcinoid of the bronchus is regarded as a low-grade malignancy. ${ }^{1,2}$ Although surgical resection is the most appropriate form of therapy, the extent of resection should be limited, favoring preservation of pulmonary function. Preferred procedures include sleeve lobectomy and sleeve segmentectomy. ${ }^{1-3}$ We herein report a case of bronchial carcinoid located in the right intermediate bronchus. Treatment consisted of endobronchial resection of the tumor and resection of the intermediate bronchus with complete preservation of the pulmonary parenchyma.

\section{Clinical Summary}

A 38-year-old woman was transferred to our hospital for the treatment of a polypoid tumor causing almost complete obstruction

From the Department of Thoracic Surgery, Kanazawa Medical University, Uchinada, Ishikawa, Japan.

Received for publication Oct 22, 2005; accepted for publication Nov 7, 2005.

Address for reprints: Motoyasu Sagawa, MD, Department of Thoracic Surgery, Kanazawa Medical University, 1-1 Daigaku, Uchinada, Ishikawa 920-0293, Japan (E-mail: sagawam@ @anazawa-med.ac.jp).

J Thorac Cardiovasc Surg 2006;131:753-4

$0022-5223 / \$ 32.00$

Copyright $\odot 2006$ by The American Association for Thoracic Surgery doi:10.1016/j.jtcvs.2005.11.008 of the right intermediate bronchus (Figure 1, A). Because the accurate peripheral extent of the tumor was unable to be evaluated, our initial treatment strategy involved endobronchial resection of the tumor. Under local anesthesia, endoscopic resection using electrosurgery was performed with a flexible bronchoscope and a snare. Pathologic examination of the resected tumor provided the diagnosis of typical carcinoid.

After endobronchial resection, the extent of the tumor's base was observed bronchoscopically. Located in the medial wall of the right intermediate bronchus, the base of the tumor extended axially, and almost the entire length of the intermediate bronchus was involved (Figure 1, B). Chest computed tomography revealed no lymph node swelling. On the basis of these findings, we conducted the second stage of treatment, namely a wide resection of the right intermediate bronchus without resection of the pulmonary parenchyma.

With the patient under general anesthesia with a doublelumen endotracheal tube, a thoracotomy was performed. The pulmonary ligament was freed for mobilization of the right middle and lower lobes, and the right main and intermediate bronchi were dissected out from the surrounding tissues. The external surface of the bronchus was found to be smooth, indicating that the tumor had not penetrated the full thickness of the bronchial wall, which was later pathologically confirmed. Wide resection of the whole length of the medial wall of the right intermediate bronchus was carefully performed. The lateral wall of the intermediate bronchus was preserved (Figure 2, $A)$. Pathologic examination revealed that the tumor was completely resected. Sixteen sutures of Maxon 3-0 (Sherwood, 